\title{
Economics in systematic conservation planning for lower-income countries: a literature review and assessment
}

Article

Published Version

Albers, H. J., Maloney, M. and Robinson, E. J. Z. (2017) Economics in systematic conservation planning for lowerincome countries: a literature review and assessment. International Review of Environmental and Resource Economics, 10 (2). pp. 145-182. ISSN 1932-1473 doi: https://doi.org/10.1561/101.00000085 Available at https://centaur.reading.ac.uk/70272/

It is advisable to refer to the publisher's version if you intend to cite from the work. See Guidance on citing.

To link to this article DOI: http://dx.doi.org/10.1561/101.00000085

Publisher: NOW

All outputs in CentAUR are protected by Intellectual Property Rights law, including copyright law. Copyright and IPR is retained by the creators or other copyright holders. Terms and conditions for use of this material are defined in the End User Agreement. 


\section{CentAUR}

Central Archive at the University of Reading

Reading's research outputs online 


\title{
Economics in Systematic Conservation Planning for Lower-income Countries: A Literature Review and Assessment
}

\author{
H. J. Albers ${ }^{1}$, M. Maloney ${ }^{1}$ and E. J. Z. Robinson ${ }^{2 *}$ \\ ${ }^{1}$ University of Wyoming, USA; jo.albers@uwyo.edu \\ ${ }^{2}$ University of Reading, $U K$
}

\begin{abstract}
Lower-income countries contain much of the world's biodiversity but often lack the institutions and resources for effective biodiversity conservation. Systematic conservation planning (SCP) frameworks provide tools to identify and implement conservation areas effectively and efficiently but rarely address issues central to lower-income countries, which limits SCP's usefulness in these settings. This paper reviews SCP and discusses how to make SCP more relevant in lowerincome countries. Lower-income countries have small conservation budgets, imperfect measures of conservation costs and benefits, and unique institutions that all influence the siting, management, and implementation of protected area networks. In addition, these aspects of the lower-income country setting inform the reaction of people to a protected area, which determines the conservation effectiveness of the protected areas. Overall, the institutional and socioeconomic settings of lower-income countries create additional layers of complexity that should be incorporated into SCP frameworks at the stage of selecting reserve sites to improve the efficiency of conservation policies.
\end{abstract}

${ }^{*}$ The authors gratefully acknowledge funding from the Environment for Development Initiative, which supported this effort and fieldwork to identify questions/issues.

ISSN 1932-1465; DOI 10.1561/101.00000085

(C) 2017 H. J. Albers, M. Maloney and E. J. Z. Robinson 
Keywords: Parks, nature reserves, reserve site selection, systematic conservation planning, spatial prioritization, incomplete markets, sustainable development, property rights, enforcement

JEL Codes: Q57, Q56, Q24, Q15, O13, Q01

\section{Introduction}

Systematic conservation planning (SCP) refers to the conservation planning framework introduced by Margules and Pressey (2000) and expanded by Pressey and Bottrill (2009). SCP emphasizes explicit, quantifiable conservation goals and specific criteria for implementing and maintaining protected areas, but allows for flexible, context-specific conservation plans. SCP aims to improve outcomes from conservation activities in part by planning at a broad level rather than focusing on one specific location at a time, and in part by reducing existing biases, such as the preponderance of reserves located in remote areas (Margules and Pressey, 2000). By taking a landscape approach, and providing a framework for the allocation of scarce financial resources, SCP that includes explicit economic analysis can assist policy makers in achieving conservation goals more effectively. In addition, SCP that incorporates economic analysis can avoid unintended consequences caused by people's reactions to conservation plans (Polasky, 2006). Yet, the implementation of these frameworks has not been widespread. Moreover, even though much of the SCP literature considers case studies or examples in lower-income countries, little in these frameworks addresses the particular characteristics of those settings that are likely to influence the actual conservation benefits generated by conservation policy there. These aspects include the difficulties of acquiring land given the diverse and often poorly defined property rights over land; the high direct dependence of rural people on the resources that are often located within planned reserves; the costly and challenging enforcement of access restrictions; and the complexities of accounting for how resource-dependent people will respond to access restrictions and of how that response determines the de facto conservation benefits provided by the reserve network. 
The need for a more systematic approach to biodiversity conservation is particularly timely. The signatories of the Convention on Biological Diversity (CBD) have agreed to achieve the Aichi Biodiversity Targets of $17 \%$ of terrestrial area and $10 \%$ of marine areas in protected areas (PAs) by 2020 (Pereira et al., 2013). Thus, with or without SCP, many countries, especially lower-income countries, that have not yet achieved these targets are likely to dramatically expand their PA systems, both terrestrial and marine, in the coming years. Many have already rapidly increased the fraction of their lands in conservation networks. For example, between 2000 and 2014 the fraction of land in conservation networks in sub-Saharan Africa expanded by 39\% (The World Bank 2015). More broadly, lower-income country marine PA systems increased by $85 \%$ during this timeframe (The World Bank 2015). The number of countries that have achieved or are on track to achieve the Aichi Target 11 on PAs varies across regions. In Africa, 4 of 46 countries are on track, with $39 \%$ of countries already achieving the goal for terrestrial areas and 3 countries achieving the goal for marine settings (UNEP-WCMC, 2016a). Similarly, 6 of 32 countries in the Asia/Pacific region are on track for meeting this target, and 9 of 23 countries in the Latin America and Caribbean are on track for the target overall but 17 countries already meet the terrestrial target (UNEP-WCMC, $2016 \mathrm{~b}, \mathrm{c})$. Given the relatively small areas of these countries' lands currently situated within reserves, lower-income countries will need to continue their rapid expansion of PA networks to achieve the Aichi targets.

Given these planned high levels of lower-income country PA expansions, this paper reviews and assesses the SCP literature and the conservation economics literature to inform SCP in lower-income countries. First, the paper provides a brief overview of the SCP literature with particular reference to the reserve site selection literature and the software used to define reserve networks. The following section considers the economics literature on siting, sizing, management, and effectiveness of PAs. Section 4 begins the focus of this literature review and critique on the lower-income country setting in its review of the role of costs, enforcement, park effectiveness, reactions to PAs, resource dependence, buffer zones, and poverty goals in the SCP and the economics literatures. The penultimate section discusses the "implementation gap" between 
research and conservation planning in practice, the potential for integration of economics in SCP in a broad sense and to incorporate lower-income country characteristics, and modifications to the software for that integration. The final section concludes while emphasizing that integrating people's response to PAs in a lower-income country setting into the decision framework for reserve location, size, and management improves the efficiency of conservation activities.

\section{SCP on PA Siting/Sizing/Management}

\subsection{Overview}

Within the broad SCP framework, Pressey and Bottrill (2009) outline 11 planning stages: stages 1-4 identify stakeholders, conservation goals, budgets, and other contextual considerations; stages 5 and 6 gather social, economic, biological, and ecosystem data; stages 7 and 8 set conservation objectives; stage 9 selects conservation areas; and stages 10 and 11 implement conservation plans and ongoing PA management. The academic literature in a range of fields, including economics, focuses on the stage 9 selection of conservation areas, often technical mathematical tools to select optimal reserve sites based primarily on ecological criteria and spatially explicit costs (Kukkala and Moilanen, 2013; Pressey and Bottrill, 2009 Williams et al., 2005; Sarkar et al., 2006). In contrast to economic efficiency, reserve designs developed in stage 9 are often altered to address social, institutional, and economic realities during the implementation stages. This article explores the economic models of people's behavior and their inclusion in the reserve site selection stage of SCP to improve the conservation outcomes from the implemented reserve network.

\subsection{Conservation Prioritization/Reserve Site Selection}

The selection of conservation areas using mathematical modeling (stage 9 of the SCP framework) has been the focus of much of the academic literature. The research in ecology, biology, economics, and operations research journals emphasizes designing mathematical tools to select reserve sites based on primarily ecological and biological criteria, while including some measure of conservation costs. Conservation value is 
maximized subject to a constraint - the set coverage problem where the constraint may be a number of sites or a total cost - or a cost or parcel number is minimized subject to a conservation objective. Solving these reserve site selection (RSS) or spatial prioritization problems typically involves heuristic algorithms or integer programming.

Originally formulated in the conservation biology literature, heuristic algorithms use iterative processes to select units of land for inclusion in (or exclusion from) the proposed set of reserve sites (Kirkpatrick, 1983; Margules et al., 1988 Pressey and Nicholls, 1989). Conservation scores assigned to land units typically reflect the presence/absence of species and the degree of protection already afforded each species, which implies that the score of a unit of land depends on what other units are selected for protection. In these heuristic algorithms, units of land are generally selected (or removed) based on their scores with the objective of producing a set of reserved sites that meets conservation criteria (Margules et al., 1988). The algorithm often selects the next unit of land based on the number of species that the existing reserve doesn't contain, following the concept of "complementarity" in the biology literature (Vane-Wright et al., 1991) and using a "greedy" algorithm in operations research (Önal, 2004). Although increasingly sophisticated, these methods retain their emphasis on ecological or biological criteria rather than extending to include socioeconomic criteria (Pressey et al., 1997; Rodrigues and Gaston, 2002; Siitonen et al., 2002).

Integer programming techniques from the operations research literature were recognized as applicable to the reserve site selection problem shortly after the introduction of heuristic methods (Church et al., 1996; Cocks and Baird, 1989; Underhill, 1994). The two primary formulations of the reserve site selection problem differ in the objective and constraint. The set covering problem finds the lowest number of land units or land costs to achieve a conservation target. The maximal coverage problem maximizes an ecological outcome subject to a constraint on the number of land units or land costs (Camm et al., 1996; Church et al., 1996; Önal, 2004). Integer programming (IP) approaches provide exact solutions but require that the objective functions and constraints be linear (Williams et al., 2004), although linearization techniques can accommodate more complex problems (Camm et al., 2002).

Many papers compare and discuss preferences across integer programming and heuristic algorithms (Csuti et al., 1997; Önal, 2004; 
Pressey et al., 1996; Rodrigues and Gaston, 2002; Vanderkam et al., 2007; Williams et al., 2004). The disadvantage of heuristic algorithms is that they do not provide true mathematical optima, and there is no way to determine the degree to which the solution is suboptimal. The advantage of heuristic algorithms is that they can handle more complex problems (e.g., larger landscapes or nonlinearities) and can reach solutions quickly when optimal IP solutions might be impossible or timeconsuming to reach (Pressey et al., 1996; Underhill, 1994; Williams et al., 2004). Some researchers argue that this advantage may be exaggerated, especially as computing power has increased (Vanderkam et al., 2007). In practice, problems are often formulated as integer programming problems and then solved using heuristic algorithms.

Researchers have extended RSS models by incorporating connectivity and boundary requirements using both heuristic and integer programming methods (Bedward et al., 1992; Moilanen, 2005; Nalle et al., 2002; Onal and Briers, 2003; Önal and Wang, 2008; Orestes Cerdeira et al., 2005; Tóth et al., 2009; Wang and Önal, 2016; Williams and ReVelle, 1998). Although optimization on stylized, small landscapes proves possible and illustrative, currently, larger landscapes require heuristic approaches if the conservation value depends on the spatial configuration of the habitat (Albers, 1996; Moilanen, 2005). Other research has introduced uncertainty in conservation values (Billionnet, 2011; Cabeza et al., 2004; Carwardine et al., 2010; Haight et al., 2000; Meir et al., 2004; Moilanen, 2005; Polasky et al., 2000; Wilson et al., 2005) and dynamic optimization (Costello and Polasky, 2004; Dissanayake and Önal, 2011; Harrison et al., 2008; Sabbadin et al., 2007; Snyder et al., 2004; Tóth et al., 2011).

Social, political, and economic factors are rarely integrated into RSS models as anything other than a fixed component of the value or cost assigned to a unit of land. Instead, assumptions about behavior guide the design of constraints. For example, in addition to a cost constraint, a limit on the boundary length of a conservation area reduces edge effects, including those posed by people interacting at the border of the reserve (see Onal and Briers, 2003). Human threats to conservation, including the threat of development and resource use, have been included in models this way (Messer, 2006), but economic or social behavior as it relates to the reserve site configuration is not explicitly modeled often. Section 3 discusses the contributions of economists to the reserve site 
selection literature, including some land price reactions to reserve siting and explicit models of people's behavior in reaction to reserve sites.

\subsection{RSS Software}

Although TNC and WWF both use Marxan, a popular conservation prioritization software package, Marxan's successful application has been mostly limited to conservation projects in higher-income countries, and more specifically to the siting of marine protected areas (Airamé et al., 2003; Lewis et al., 2003; Loos, 2011). Many academic case studies use Marxan to create hypothetical conservation reserves using real data, with many examples of higher-income country settings (Ceausu et al., 2015; Delavenne et al., 2012; Watts et al., 2008a; Watts et al., 2008b), possibly due to the better availability of ecological, biological, and cost data. However, the software has also been applied to conservation scenarios in developing countries, including Papua New Guinea (Green et al., 2009), the Solomon Islands (Game et al., 2011), and the Democratic Republic of the Congo (Nackoney and Williams, 2013). Marxan software uses the set covering approach to choosing the optimal reserve site set and simulated annealing as the heuristic solution method (Watts et al., 2008a; Watts et al., 2008b). Sets that fail to meet objectives or that increase boundary length incur "cost" penalties.

In contrast to Marxan, another popular conservation prioritization software, Zonation, uses the maximal coverage problem formulation for selecting reserve configuration, which frames the problem as maximizing conservation benefits subject to a cost constraint. Zonation uses a heuristic algorithm that selects a reserve configuration by initially assuming the entire landscape is conserved and iteratively removing the land units that cause the lowest marginal reduction in conservation goals (Rayfield et al., 2009). Zonation has the ability to alter the marginal conservation value of a land unit based on ecological interactions such that the presence of a species or resources in nearby units of land (or, inversely, their absence) alters the conservation value of the unit. Zonation can also integrate uncertainty about the presence of species and the adherence of the reserve design to specific plans or geographic features (e.g. rivers). Zonation has been used less frequently in the conservation planning literature than has Marxan, but some unique studies highlight the greater flexibility of 
Zonation. For example, Rayfield et al. (2009) incorporates predatorprey interactions into the Zonation algorithm. Zonation software has also been applied to the design of protected areas in Finland (Arponen et al., 2012) and Australia (Whitehead et al., 2014). In the latter study, the social values with respect to conservation of local populations were integrated into the conservation value of each unit of land, and attitudes toward development modified the costs of each unit.

\section{Economics Literature on PA Siting/Sizing/ Management and SCP}

Economists contribute directly to the RSS literature largely through consideration of costs and dynamics and less directly to the SCP literature in analyzing protected area/reserve locations, PA management, risks, and private conservation.

A central contribution of economists to the RSS literature involves incorporating land acquisition costs or land opportunity costs into RSS problems in settings with heterogeneity in those costs. The inclusion of costs changes the goals or constraints of the RSS problem to consider a budget rather than setting a constraint on the number of reserve sites or finding the lowest number of sites to achieve a level of species protection. Considering costs leads to more conservation per budget level and generates different sets of reserve sites than the more standard RSS procedures (Ando et al., 1998). Following that article, the economics literature has considered the role of cost heterogeneity in the RSS process (e.g., Balmford et al., 2000; Polasky et al., 2001; Moore et al., 2004; Nicholson et al., 2006; Naidoo and Iwamura, 2007; Nelson, 2007) but much of the broad RSS literature continues to disregard costs or assume homogenous costs of land. Naidoo et al. (2006) review analyses of costs in SCP, distinguishing between acquisition costs, management costs, transaction costs, damage costs, and opportunity costs and emphasizing that the variation in costs typically dwarves variation in ecological variables like species richness.

Other economic analyses of reserve creation also incorporate costs as a central feature. Some focus on cost-benefit analysis and return on investment (ROI) analysis to determine which areas merit reserve 
status, also emphasizing that considering conservation costs in decisions generates higher levels of conservation per dollar (Boyd et al., 2012; Newbold and Siikamaki, 2009). ROI analysis can be used to determine least cost methods to achieving a conservation target or maximizing a conservation outcome for an amount of spending, but without converting all values to monetary terms (Boyd et al., 2015). Efficiency frontiers identify the tradeoffs between production output and conservation outcomes (e.g., Polasky et al., 2005). In a particularly landscape-perspective approach, Polasky et al. (2008) considers both ecological issues like suitable habitat and species dispersal and economic productivity's spatial variability to define tradeoffs and the highest levels of conservation benefits achievable for a level of economic outcome. That analysis includes management costs for conservation in addition to the analysis' dependence on opportunity costs in terms of lost production. Newburn et al. (2005) assess a range of targeting tools including benefit only, benefit-cost, benefit-loss, and benefit-loss-cost approaches and emphasize that ignoring habitat vulnerability or costs in conservation prioritization produces sub-optimal conservation choices. These authors found that only $13 \%$ of plans that they reviewed (in a US sample spanning 5 years) took account of the economic costs of conserving habitat. Economists have also contributed to SCP by assessing nonmarket values and/or establishing methods to evaluate conservation decisions. Incorporating valuations for nonmarket conservation benefits enables policymakers to make conservation decisions that incorporate tradeoffs in cost-benefit analysis (Chan et al., 2011).

Another thread of economics research concerning the creation of reserves uses metapopulation models of fish among patches within a bioeconomic framework to pose questions about marine reserves or other types of Marine Protected Areas in particular locations (Fox et al., 2012; Sanchirico, 2005; Sanchirico and Emerson, 2002; Sanchirico and Wilen, 2001; Smith and Wilen, 2003; Wilen et al., 2002; Zhang and Smith, 2010). The primary emphasis of this literature lies in capturing the impact of fish dispersing from protected reserve patches to other patches with legal fishing. Much of that economic analysis demonstrates that the dispersal creates enough benefits to offset lost fishing access to the reserve in relatively few settings. Schnier (2005) analyzes optimal marine reserve size in a setting of hotspots and heterogeneity across potential reserve locations. Several authors emphasize that the 
optimality of establishing a reserve depends on both ecological and economic aspects of the setting, which dovetails with this article's point about incorporating socioeconomic characteristics into reserve selection decisions (e.g., Sanchirico and Wilen, 2001).

Although most RSS studies examine deterministic settings, uncertainties about economic and ecological processes and values should alter decisions about reserve site selection. Even in static analyses, uncertainty about the presence/absence of species merits a probabilistic characterization of species locations and the use of an expected species conserved metric for reserve decisions (e.g., Polasky et al., 2001). Most RSS analysis assumes that a species on a parcel within a reserve is "covered" or protected. Albers et al. (2016a,b), however, considers the risks to species within reserves from habitat-destruction, also by using a probabilistic assessment of the species protected by a reserve network facing stochastically arriving hazards. In addition, that article also shows the less agglomerated pattern of reserve sites in the optimal reserve network for the case of spreading hazards such as fire, invasive species, or pests.

Similarly, given their oft-permanent status, reserve decisions should reflect the dynamics of ecological and socioeconomic processes. Dynamically optimal economic decisions about reserve selection prove computationally difficult due to dimensionality issues, especially with uncertainty or stochasticity. Still, the land markets introduce a dynamic component into the costs of acquiring land for reserves such as when conservation increases the price of remaining land due to a lower supply of land or due to high amenity values near reserves. Costello and Polasky (2004) use a stochastic dynamic integer programming formulation to determine optimal consecutive reserve selections when a budget constraint prohibits selection of all selected sites immediately and when unreserved sites may be irreversibly developed. Armsworth et al. (2006) model how conservation acquisitions alter nearby land values in ways that can accelerate development near reserves. Continuing with this line of market feedbacks, Dissanayake and Önal (2011) incorporate spatial characteristics into a dynamic model of price feedback effects in a site selection framework. Butsic et al. (2013) use property price and land development models incorporated into a reserve selection method that demonstrates that land market feedbacks can be included in optimal 
reserve network design and that the value of that undertaking varies across landscapes.

As emphasized in the ecology literature, conservation outside of public reserve networks plays a critical role in creating conservation benefits at a landscape level and so should be included in SCP. The economics literature includes analysis of mechanisms to encourage the private production of public goods, the conservation actions of private actors, and the role of the demand for conservation. Newburn et al. (2005) links their several methods for targeting reserve locations to nonacquisition mechanisms, such as payments or easements, to induce conservation on private land. Other economists also examine easements in a range of settings, from marine to farm to forest (Deacon and Parker, 2009; Plantinga, 2007). Several authors examine methods to induce private landowners to generate socially preferred configurations of conservation, such as through agglomeration bonuses, incentive payments, or auctions (e.g., Polasky, et al., 2014; Williams, et al., 2012; Drechsler et al., 2010; Parkhurst and Shogren, 2007; Parkhurst et al., 2002; Stoneham et al., 2003). Albers and Colleagues (Albers and Ando, 2003; Albers et al., 2008a,b) examine spatial patterns of conservation through both private land trusts and public organizations through modeling and empirical analysis, reflecting the impact of interactions of actors in determining the spatial pattern of conservation. In a rare departure from emphasis on the supply of conservation, Ando and Shah (2010) demonstrate how the location of people that demand conservation relative to locations that produce conservation benefits leads to optimal conservation of sites that reflect conservation outputs declining over distance from the productive area and conservation value increasing with proximity to populations of conservation demanders.

Overall, economics contributes to the SCP literature in ways that reflect how the nonbiophysical aspects of a setting influence optimal conservation reserve policy. That literature, however, tends to emphasize decisions in settings with well-functioning institutions, including property rights. That often-implicit assumption permits an emphasis on socioeconomic characteristics such as land acquisition costs and land markets. Lower-income settings, however, introduce further complications that limit the usefulness of the SCP frameworks to those countries. 


\section{SCP and Economic Analyses in Lower-Income Country Settings}

The lower income country setting poses particular challenges to locating reserve networks, stemming particularly from often-imperfect institutions, direct resource dependence, anthropogenic threat to resources even within reserves, and low budgets. The outcome of any conservation policy derives from the reactions of people to that policy but the very concept of a park or reserve comes from a higher-income country perspective where institutions function and people rarely depend directly on the resource base (Hough, 1988; Lusigi, 1984; Polasky, 2006). In the case of new nature reserves in lower-income countries, both local people and "outsiders" interact with resources in and outside of the protected area, which contributes to how the reserve and landscape produce benefits (Ewers and Rodrigues, 2008; Robinson et al., 2014). In lower-income countries, the particular institutional and socioeconomic setting mitigates the land and resource decisions of people in response to the conservation policy, which generates costs and anthropogenic risk to the reserves. This section discusses how the characteristics of lower-income countries generate reserve costs, management considerations, and landscape impact that, for economic efficiency, should inform reserve site selection and broader SCP.

\subsection{Institutions}

Several characteristics of institutions governing land use in lower-income countries can confound or complicate conservation policy. Institutions for land management and ownership include: regions with incomplete or costly access to markets, rendering markets less than perfect; thin land markets; poorly defined or contested property rights and/or legal systems that inadequately support such rights; rural people extracting resources directly rather than using markets, often for subsistence use; de jure property rights resting with the government but historical or de facto rights accruing to households and communities; and community or common property management institutions rather than individual land ownership (e.g., Carter and Olinto, 2003; Ostrom and Hess, 2010). The lower-income country property rights institutions create important issues for reserve networks and conservation efforts. In particular, weak property rights force landowners, whether individuals, communities, 
or governments, to incur monitoring and enforcement costs to prevent extraction and conversion of land. Property rights issues also limit the use of incentive policies that depend on well-defined land tenure regimes, such as easements and payments for ecosystem service programs. People react to reserve networks and SCP initiatives through the particular institutional setting.

\subsection{Costs}

As discussed earlier, the costs of establishing reserve networks prove fundamental in determining the optimal reserve sites, although many lower income countries have large areas of public land, which implies zero direct acquisition costs but nonzero opportunity costs. In addition, lower-income country conservation organizations, including government institutions, face different costs than their high-income country counterparts and serious budget constraints (Adams et al., 2010; Bruner et al., 2004; Naidoo et al., 2006; West et al., 2006). Socially efficient selection of reserves requires assessment of the full range of costs. The market costs of acquiring land and managing reserves reflect property rights institutions and the often-ignored nonmarket costs incurred by local people and the landscape as a whole reflect people's decisions in the institutional setting. To date, more attention has been paid to the market acquisition costs than to the social and economic impact of reserves that constitute nonmarket costs (Adams et al., 2010).

Basing estimates of acquisition costs on the opportunity cost of land in terms of foregone uses such as agriculture in lower-income countries can mask the true total social costs of acquiring land in settings with poorly defined property rights and with thin markets (Adams et al., 2010). For example, in rural settings, the typical estimate of the opportunity cost of the land may prove low due to low-valued agriculture but that characterization of the opportunity cost misses other aspects of the rural setting. Landowners may value the land more highly due to subsistence considerations, long-standing community relationships, squatter's rights in the absence of fully documented ownership, or the lack of land for sale to replace the owned or occupied plot. In addition, acquiring land in lower-income countries can be contentious - even if at low monetary cost - because of overlapping claims to the land. Still, Bruner et al. (2004, p. 1124) note that "protected areas created to date 
[in lower-income countries] have generally not required land purchase or compensation" due to de jure government land ownership. In that case, nonmarket, nonacquisition, management, and enforcement costs should play a larger role in defining optimal reserve sites for inclusion in a network. Even conservation organizations that do not consider social costs in their conservation decisions must include management and enforcement costs to achieve the highest levels of conservation for their budget.

While in higher-income countries, efficient legal systems reduce the cost of enforcing a state property right over a PA; in lower income countries, PA management requires enforcement of the property right to that area against encroachment and land conversion and against resource extraction (Albers and Grinspoon, 1997; Fischer, 2008; Hayes, 2006; Wätzold and Schwerdtner, 2005). Bruner et al. (2004) and others suggest that few PA systems have large enough budgets available to deter all illegal use of PA land and resources. Although these costs comprise a considerable fraction of many PA budgets, few academic or practical PA site selection frameworks incorporate those costs into reserve design decisions. In addition, the level of those costs vary over time and space as a function of reserve characteristics including resource quality and boundary length, socioeconomic characteristics of the surrounding population, and market setting. Overall, enforcement costs vary with the threat or risk to the protected area, which derives from the strength of legal and property rights institutions.

PAs in lower-income countries impose costs on populations that are displaced when the PA is introduced (Ghate, 2003; Rangarajan and Shahabuddin, 2006; Robinson et al., 2011), including market and nonmarket costs of resettlement. In addition, because poor households in lower-income countries often depend directly on the resource base, the introduction and enforcement of a protected area that limits access to resources can impose costs on those people as they must attain the resources elsewhere or reduce their use of resources (DeFries et al., 2010). Ferraro (2003) estimates the opportunity cost of a national park in Madagascar on its neighbors and finds high costs relative to household incomes but low total costs from an international perspective. Broader analyses that use econometric analysis with matched controls find that ecosystem protection leads to poverty alleviation, although these analyses cannot identify mechanisms for that trend (Andam et 
al., 2010; Ferraro et al., 2011). Robalino and Villalobos (2015) find evidence that wages near park entrances appear higher than in other areas, perhaps due to in-migration to those areas rather than an impact of the park on local people.

Conflict produces social costs for both local people and managers (Hough, 1988; Maikhuri et al., 2000) and may occur when locals contest the legitimacy of an exclusionary conservation area, groups of local people benefit differentially (West et al., 2006), or the protected area imposes costs on resource-dependent people. Human-wildlife conflicts (e.g., Dickman, 2010) and human-human conflict between users and guards lead to social costs (Balmford et al., 2001; Lewis, 1996; Luck et al., 2004; Woodroffe et al., 2005; Robinson et al., 2010). Although implementation of parks typically employs methods to involve local people, conflicts between locals and parks still occur. In addition, conflicts between local people and "outsiders" who extract in PAs also create social costs in the vicinity of PAs.

Given systematic conservation planning's emphasis on landscapes rather than individual sites, the impact of a particular reserve site on people's interactions with other parts of the landscape can also create an off-site cost of a reserve. Leakage of ecosystem degrading actions from the now-protected area to other locations occurs as people respond to enforcement of access restrictions but unchanging resource needs by relocating some or all of their activities to unprotected areas (Albers and Robinson, 2011; Robinson et al., 2013).

\subsection{Park Effectiveness and Anthropogenic Threats To Reserve Resources}

Although some of the RSS literature incorporates aspects of threats or hazards to species or resources in determining reserve sites, much of the prioritization literature ignores threats to resources included in reserves. In lower-income countries, the demand for resources paired with the lack of reserve enforcement implies that anthropogenic pressure occurs within reserves. Reserves in lower-income countries may be deliberately sited in low-population areas deemed unsuitable for human use (Andam et al., 2008; Joppa and Pfaff, 2009). In such cases, this siting can make the reserve appear successful despite the reality that this land and biodiversity were not under anthropogenic pressure, limiting the need 
for the reserve (Ferraro and Pattanayak, 2006). In this situation, the park creates little "avoided deforestation" because little deforestation would have occurred in the park's absence.

Several statistical analyses determine that parks do lead to avoided deforestation (e.g. Andam et al., 2008; Ferraro et al., 2013, 2011). These studies use matching between park parcels and similar unprotected parcels to determine appropriate controls for comparison of the deforestation rates in and outside of parks. Like other deforestation analyses, however, these techniques rely on parcel characteristics such as soil quality and distance to markets rather than focusing on decisions to deforest directly. Although Pfaff et al. (2014) find differences in PA effectiveness across IUCN classification, none of these studies incorporates the market setting in which people make decisions; the property rights institutions in the region; nor the enforcement and management conducted by the PA to deter deforestation. Overall, these empirical assessments find that even the most effective PAs incur some deforestation within their boundaries; anthropogenic threats to ecosystem continue after reserve siting and establishment.

\subsection{Reactions to Reserves}

To incorporate these common anthropogenic threats to reserves into the reserve siting and management decisions would require understanding the decisions of the actors posing those threats. A small but growing literature uses spatial economic decision models of resource-dependent households to demonstrate how villagers react to a reserve depending on the institutional and socioeconomic setting (Albers, 2010; Albers and Robinson, 2011, 2013; Muller and Albers, 2004; Robinson et al., 2013, 2011, 2002, 2008). Given their spatial structure, these studies also identify how this reaction affects the effectiveness of the reserve in isolation and within a landscape.

Conceptually, an individual resource extractor can respond to a new reserve by choosing to collect less, to rely more on markets for the same or a substitute good, to change extraction locations, or continue to extract in the reserve illegally. Robinson et al. (2002) and Albers and Muller (2004) demonstrate the high dependence of these decisions on local institutions such as access to resource labor markets. For example, 
if the reserve has full enforcement with well functioning markets, little leakage of extraction into other areas and little impact on households' welfare occur. If markets function poorly, then leakage occurs at the landscape level. Without complete enforcement, extractors make tradeoffs between illegal extraction - an anthropogenic threat within the reserve itself - and leakage of extraction to other locations - an anthropogenic threat to the extra-reserve landscape. The interaction of enforcement, socioeconomic setting, and resource characteristics determine the extraction decisions of rural people, and thus the effectiveness of the reserve.

The law and economics literature demonstrates that costly enforcement typically implies that some illegal activity will optimally occur either due to greater marginal costs than benefits of deterring all such activity or enforcement budget constraints binding below the first-best level of enforcement (e.g., Becker, 1968; Shavell and Polinsky, 2000). In the lower income country conservation setting, due to the high costs of enforcement and low enforcement budgets, funding is typically insufficient to exclude people fully from the reserve, which implies ongoing illegal extraction (Robinson et al., 2010). The conservation area's manager acts as the "principal" in defining the level of monitoring while considering the response of the "agents," here extractors or deforesters, in a principal-agent framework. In cases of such incomplete enforcement, how a reserve manager uses that budget with respect to enforcement effort influences the overall impact, and thus effectiveness, of the enforcement and, in turn, the conservation reserve. With spatial aspects to the reserves themselves and to the agents' decisions, to achieve the highest conservation benefits in the case of costly enforcement, Albers (2010) demonstrates that optimal reserve monitoring efforts are spatially triaged to reflect that no benefit arises from patrols where people would never choose to extract — such as far from the village - and that no benefit arises from enforcement if it is not sufficient to deter the illegal activity — such as close to the village. For a simple landscape of a reserve surrounded by villagers, limited enforcement effort is best located in a ring, leaving a naturally protected inner "core" and an unprotected outer "buffer zone" (Albers, 2010; Johnson et al., 2012). Sims (2014) builds on this model and tests its implications in Thailand, finding that focusing limited enforcement within an inner core 
of a protected area most effectively deters clearing of the interior and forest fragmentation, compared with boundary enforcement or the use of agglomeration bonuses.

Further theoretical modeling suggests that when markets are not functioning efficiently, trying to protect a larger reserve may be less effective than concentrating on fully protecting a smaller reserve (Robinson et al., 2011). Moreover, if managers value the ecosystem services provided by the broader landscape, then reserve siting and management decisions must reflect the potential for significant extraction leakage. Albers et al. (2016a,b) incorporates fishers' location and labor choices in response to imperfectly enforced Marine Protected Areas (MPAs) into an optimal MPA siting, sizing, and management framework. In that analysis, ignoring the reaction of fishers to the MPA or assuming complete deterrence of fishing within the MPA despite low budgets leads to inefficient locations and sizes for the Marine Protected Areas. Incorporating the reaction of fishers to the MPA at the stage of selecting the sites and enforcement levels for the MPA insures that the MPA choices reflect the post-policy and post-reaction level of conservation benefits created in the marinescape. In addition, policy makers that consider the impact of an MPA on livelihoods require a broader perspective still, with tradeoffs between conservation benefits, yield, and incomes that require recognizing the decisions of fishers in response to the MPA policy.

\subsection{Poverty Goals and Impact}

Many initiatives and conservation policies explicitly aim to improve conservation outcomes while also reducing poverty, and economists have examined those links (Adams et al., 2004; Naughton-Treves et al., 2011; Naughton-Treves et al., 2005; Ferraro and Hanauer, 2011; Muller and Albers, 2004; Naughton-Treves et al., 2011; Sims, 2010). For example, Tanzania's marine PA legislation requires that Marine Protected Areas provide both biodiversity conservation and poverty alleviation (URT 1994). Having dual goals for PAs implies that reserve selection decisions need expansion to incorporate multiple objectives, socioeconomic and institutional information, and frameworks that depict the impact of decisions of people in response to the reserve on both anthropogenic threats to the reserve and income levels. 


\subsection{Summary}

Overall, the lower-income country setting for reserves contains different costs and institutions that should be considered in choosing the site, size, and management of reserves. With insufficient funds or property rights institutions to enforce access restrictions to PAs, reserve siting decisions should reflect the actions of people that threaten resources even within reserves due to low enforcement and high resource dependence by local communities. The enforcement costs of a PA are a function of the market settings and the livelihood decisions of local people, and are ongoing. In addition, land acquisition costs proxied by the opportunity cost of the land in small-scale agriculture may fail to represent the land value to local people, especially in thin land market settings and in settings of traditional land rights conflicting with de jure rights. Reserves also generate costs in terms of conflict and livelihoods to local people. Understanding the full range of costs of reserves as a function of the people's response to the reserve in different socioeconomic and ecological settings provides a first step toward socially optimal SCP that incorporates characteristics of the lower-income country setting within the reserve selection or spatial prioritization portion of reserve planning stages.

\section{Integrating Economics and SCP: Addressing People}

Economic focus on people's decisions, values, and tradeoffs provides potential for economic frameworks to contribute both to the determination of optimal reserve networks and to the implementation of those networks.

\subsection{The Implementation Crisis}

The "disconnect" between the academic literature, including the numerous RSS techniques, and the implementation of real-world conservation projects has been referred to as the "research-implementation gap" (Knight et al., 2008; Santangeli et al., 2014) or "implementation crisis" (Biggs et al., 2011). Knight et al. (2008) review all conservation assessments published in English language academic journals from 1998 to 2002, and use survey data to determine if the assessments led to 
any form of implementation. They find that implementation actions only occurred for $33 \%$ of the assessments, and only $13 \%$ of the implementation actions were considered "highly effective." The authors conclude that greater implementation will require better recognition of the opportunities and constraints faced by practitioners, and recommend an expansion of the consideration of social dimensions in conservation research. Such considerations seem consistent with a community-based, collaborative approach to resource management and conservation, and pose a challenge for technical models, which are limited in their capacity to consider such factors.

Knight et al. (2011a) argue that academic conservation planning focuses on the "where" of conservation but ignores the "how," in part due to the interdisciplinary nature of implementation strategies. The implementation crisis literature identifies social and economic factors as the most critical barriers to implementation, including the management of stakeholder conflicts (Biggs et al., 2011) and the willingness of landowners to sell their land (Knight et al., 2011b). Knight and Cowling (2007) argue for opportunistic conservation, which is often done in practice but leaves little role for technical RSS tools. Chomitz et al. (2006 p. 40) conclude that:

The optimization approach focuses on where to intervene, not on how to induce landholders to comply with the plan. The result is a plan that is, in theory, efficient in achieving the specified goal, but in practice may not be implementable because it relies on compulsion, which is politically costly, or on nearly universal cooperation of designated landholders, which may not be forthcoming.

In addition, the political economy at both the local and national scales can influence or constrain the implementation of conservation plans. Although SCP often includes steps to involve or understand local communities, that inclusion rarely occurs in the stage of determining the location, size, and shape of reserves, which may further limit the ability to implement optimal plans.

\subsection{Lower-Income Country Settings}

First, the emphasis of economics in SCP on costs is appropriate but, in practice, those costs do not reflect imperfect institutions, resource 
dependence, and cash-poor managers, which implies that incorporating costs into SCP will emphasize different costs in a lower-income country setting. In settings with thin land markets and ill-defined and protected property rights, land acquisition costs may reflect only a fraction of the true expenses incurred in securing land for reserves. For example, landowners may require far higher land prices than the economic opportunity cost of their land implies due to historical and community ties and to the inability to purchase similar land. In addition, the long-term costs of enforcing reserve property rights against encroachment and degradation have proven large in most lower-income country settings yet those costs rarely enter the reserve siting decisions themselves. Economic analysis that uses site characteristics to estimate land costs does not incorporate the true total opportunity cost of land to landowners nor the ongoing enforcement costs common in lower-income country settings.

In addition, estimating costs and deforestation risk as a function of the characteristics of land units based on a von Thunen approach does not incorporate economic information about people's land and resource use decisions in reaction to a PA. Models of people's decisions in the institutional and ecological setting, described earlier, provide information about the amount and locations of avoided deforestation and degradation under different PA networks and under different management regimes. That information could be incorporated into the reserve selection portion of SCP where the reserve selection is based not on the characteristics of the areas prior to the reserve policy but instead on the predicted characteristics of the reserve following optimal management subject to budget constraints and considering the reaction of people to that management. Incorporating models of people's response to reserves and reserve management into reserve selection and management decisions would produce reserve siting decisions based on both ecology and socioeconomic characteristics of the setting, with a fuller appreciation of the management costs and ecological losses associated with any particular reserve decision. In addition, the spatial decision frameworks described earlier can predict locations that will require more/less enforcement and, in keeping with the landscape focus of some systematic conservation planning approaches, identify the likely location and size of leakage. Integrating ecology and socioeconomics into the fabric of the decision process will produce more efficient reserve networks, especially in contrast to the current strategy of addressing 
the actions and needs of people after defining the reserve based largely on ecological considerations.

\subsection{Where Should Economists Focus their Research to Inform SCP?}

The inclusion of people's reaction to PAs in the decision framework that defines those PAs require at least three areas of economic research. First, the current models of people's behavior in response to PAs reflect observations but remain highly stylized. Augmenting those models with empirical, experimental, and behavioral insights into resource and land use decisions in a range of settings would further improve the ability to site reserves in ways that lead to high levels of conservation benefits even after people respond. Second, most valuation exercises and many ecological metrics to characterize conservation benefits do not depict how those benefits vary with different levels and types of human use of the resource, such as occurs in incompletely enforced reserves and in extractive reserves. Further study at the intersection of ecology and economics that depicted ecological outputs as functions of human interactions with the resource would facilitate SCP by identifying tradeoffs between conservation and poverty goals, demonstrating where less restrictive IUCN classifications for PAs can generate both ecological and socioeconomic benefits, and more accurately depicting the costbenefits of different reserve siting and management combinations. Third, further economic analysis of the effectiveness of different management actions in promoting conservation, including enforcement, livelihood projects, payments, and buffer zone enhancement, would enable SCP to consider siting and management decisions jointly. Taken together, these lines of research might combine to define ecological production functions as a function of reserve location, management, and budgets for a range of ecological, socioeconomic, and institutional settings.

\subsection{Data Needs For Economics in SCP in Low-Income Country Settings}

Incorporating institutional characteristics and people's response to conservation areas into SCP's choices of PA location, size, and management at the point of spatial prioritization will require data that describe those characteristics and decisions, in addition to modeling to define 
feedback loops between policy, conservation benefits, and people's actions. Data from surveys could define the relative value of labor time spent in various activities including resource extraction that, when combined with household decision models, would identify the likely response to PA policies including enforcement, labor-absorbing alternative income-generating opportunities, and projects, which alter the relative benefits of resource-degrading activities in the PA. Similarly, with market access costs as a determinant of the amount, location, and intensity of resource extraction, surveys that characterize which people interact with markets for what products would allow SCP to site PAs in locations, or to propose enforcement mechanisms, that reflect the local market conditions' impact on people's decisions to cooperate with PAs (Robinson et al., 2002). Analysis of local government documents describing resource management institutions - such as Tanzania's "village environmental committee" records - and actions could also be incorporated into models of people's responses to PAs, as mitigated by such local management institutions. Many village governments and PA managers maintain records of enforcement activities including time spent patrolling, types of illegal activities found, and outcomes of adjudications. Augmenting those data with spatial information about the patrol routes and frequencies through GPS tracking of guards, and with information on monitoring budgets and costs, would allow for further understanding of the enforcement decisions and costs required to achieve a desired level of conservation within a PA. In many settings, SCP collects some such local information through surveys and participatory meetings prior to designation of a PA, but rarely combines such data with models of human behavior to characterize the size and locations of the anthropogenic threat to resources and use that information in the spatial prioritization process.

\subsection{Technical Issues in Bringing Economics into SCP}

Integrating economic behavior into existing conservation software packages would improve the applicability of these packages to the lowerincome country context with relatively little cost to practitioners. Both Marxan and Zonation are capable of integrating social variables, such as enforcement costs and vulnerability to illicit harvesting, as spatiallyexplicit costs if those costs are assumed to be independent of the PA 
design. Neither software package is designed to model economic behavior in a manner that allows people's reactions to depend on the hypothetical configuration of the reserve, although the minimization of boundary length makes implicit assumptions about how economic and social interactions are affected by reserve design. The possibility of adapting existing capabilities of the software to better reflect such economic and social interactions is worth exploring. A preliminary analysis indicates that such integration might be more likely with Zonation software than with Marxan, as interactions among local populations, enforcement agents, and natural resources could be modeled using Zonation's existing capability to model ecological interactions.

\section{Conclusion}

As many lower-income countries expand their terrestrial and marine PA networks, systematic conservation planning decision frameworks contain little about the socioeconomic characteristics of those specific settings that should inform expansion decisions. Even though it is widely accepted that the biggest threat to biodiversity comes from human land use decisions, human threats to ecosystems within reserves are less well known and understood despite park effectiveness statistical analysis that finds variation in those threats and ongoing deforestation in many parks. In settings without near-perfect enforcement in, or cooperation with, protected areas, the ongoing reaction of resource-dependent people ultimately determines both the ecological and economic outcomes of any protected area or reserve network. Even with effective enforcement, at the landscape level, the extent to which people displace activities from a now-protected site into the surrounding areas determines broader reserve effectiveness. With reserve siting frameworks largely ignoring the impact of people on the outcomes that will actually derive from a reserve, these frameworks site reserves in ways that produce fewer benefits than could be achieved by recognizing the impact of people. Although some implementation programs incorporate people and their needs in various ways, that process typically adjusts the reserve sites and management in a post-optimal decision stage, which limits the conservation benefits achieved. Economic efficiency - the pathway to the highest level of conservation benefits for a given expenditure 
level - requires that people's actions be considered during the optimization to define the reserve, rather than tacked on for social cooperation later.

This literature critique identifies several characteristics of lowerincome countries that, if incorporated into economic analysis and into SCP, would provide more effective guidance to SCP in these settings. First, the costs involved with siting and maintaining a PA in low income countries may be higher than expected due to individual and community reluctance to sell land even if they have property rights and to the ongoing nature of enforcement costs for the PA property right in a setting where both local people and outsiders seek access to land and resources within the reserve. Second but related, the human threats to the ecosystem services produced within PAs both continue and evolve over time as the socioeconomic setting evolves. The explicit assumption in much of the RSS literature that species or ecosystem services are permanently protected within a reserve doesn't apply in the presence of natural or human threats to the resources in the PA, as appears relevant in most lower-income country settings where incomplete enforcement is common. Third, because enforcement costs are high and ongoing, and budgets are limited in lower-income countries, SCP should integrate siting, sizing, and management decisions rather than making those decisions somewhat sequentially. Fourth, de facto community management of resources, whether legally recognized or informal, further complicates the fee simple approach to acquiring land for reserves. Fifth, in the absence of perfectly enforced property rights for PAs, the ecological and economic outcomes of a PA derive from the siting and management decisions and from the reaction of people to those decisions. Furthermore, economic models and empirical investigations demonstrate that people react to conservation policies differently across socioeconomic and institutional settings, particularly across market settings. Given that economic efficiency requires that the reaction to the PA enters the decision of the choice of PAs, and that economics contributes understanding of that reaction in a range of settings. Adjusting SCP frameworks to incorporate these factors will improve the selection of reserve sites by decisions based on the expected ecological outcomes following the anthropogenic response to the reserve network. 


\section{References}

Adams, V. M., R. L. Pressey, and R. Naidoo. 2010. "Opportunity Costs: Who Really Pays for Conservation?" Biological Conservation. 143(2): 439-448.

Adams, W. M., R. Aveling, D. Brockington, B. Dickson, J. Elliott, J. Hutton, D. Roe, B. Vira, and W. Wolmer. 2004. "Biodiversity Conservation and the Eradication of Poverty". Science. 306(5699): $1146-1149$.

Albers, H. J. 2010. "Spatial Modeling of Extraction and Enforcement in Developing Country Protected Areas". Resource and Energy Economics. 32: 165-179.

Albers, H. J. and A. W. Ando. 2003. "Could State-Level Variation in the Number of Land Trusts Make Economic Sense?" Land Economics. 79(3): 311-327.

Albers, H. J., A. W. Ando, and M. Batz. 2008a. "Equilibrium Patterns of Land Conservation: Crowding In/Out, Agglomeration, and Policy". Resource and Energy Economics. 30(4): 492-508.

Albers, H. J., A. W. Ando, and X. Chen. 2008b. "A Spatial-Econometric Analysis of Attraction and Repulsion of Private Conservation by Public Reserves". Journal of Environmental Economics and Management. 56(1): 33-49.

Albers, H. J., G.M. Busby, B. Hamaide, A. W. Ando, and S. Polasky. 2016a. "Spatially-Correlated Risk in Nature Reserve Site Selection". PLoS One 11, e0146023.

Albers, H. J. and E. Grinspoon. 1997. "A Comparison of the Enforcement of Access Restrictions between Xishuangbanna Nature Reserve (China) and Khao Yai National Park (Thailand)". Environment Conservation. 24: 351-362.

Albers, H. J., L. Preonas, E. J. Z. Robinson, and R. Madrigal. 2016b. "Optimal Siting, Sizing, and Enforcement of Marine Protected Areas in Lower Income Countries". Draft in review. Available from: http: //www.bioecon-network.org/pages/18th_2016/Robinson.pdf.

Albers, H. J. and E. J. Z. Robinson. 2011. "The Trees and the Bees: Using Enforcement and Income Projects to Protect Forests and Rural Livelihoods Through Spatial Joint Production". Agricultural and Resource Economics Review. 40(3): 424-438. 
Andam, K. S., P. J. Ferraro, A. Pfaff, G. A. Sanchez-Azofeifa, and J. A. Robalino. 2008. "Measuring the Effectiveness of Protected Area Networks in Reducing Deforestation". Proceedings of the National Academy of Sciences. 105(42): 16089-16094.

Andam, K. S., P. J. Ferraro, K. R. E. Sims, A. Healy, and M. B. Holland. 2010. "Protected Areas Reduced Poverty in Costa Rica and Thailand". In: Proceedings of the National Academy of Sciences, USA. Vol. 107. No. 22. 9996-10001.

Ando, A. W. and P. Shah. 2010. "Demand-side Factors in Optimal Land Conservation Choice". Resource and Energy Economics. 32: 203-221.

Ando, A., J. Camm, S. Polasky, and A. Solow. 1998. "Species Distributions, Land Values, and Efficient Conservation". Science. 279: $2126-2128$.

Armsworth, P. R., G. C. Daily, P. Kareiva, and J. N. Sanchirico. 2006. "Land Market Feedbacks Can Undermine Biodiversity Conservation". Proceedings of the National Academy Science USA. 103: 5403-5408. Arponen, A., J. Lehtomäki, J. Leppänen, E. Tomppo, and A. Moilanen. 2012. "Effects of Connectivity and Spatial Resolution of Analyses on Conservation Prioritization Across Large Extents". Conservation Biology. 26: 294-304.

Balmford, A., K. J. Gaston, A. S. L. Rodrigues, and James A. 2000. "Integrating Costs of Conservation into International Priority Setting". Conservation Biology. 14: 597-605.

Balmford, A., J. L. Moore, T. Brooks, N. Burgess, L. A. Hansen, P. Williams, and C. Rahbek. 2001. "Conservation Conflicts Across Africa”. Science. 291: 2616-2619.

Becker, G. S. 1968. "Crime and Punishment: An Economic Approach". Journal of Political Economy. 76: 169.

Bedward, M., R. L. Pressey, and D. A. Keith. 1992. "A New Approach For Selecting Fully Representative Reserve Networks: Addressing Efficiency, Reserve Design and Land Suitability with an Iterative Analysis". Biological Conservation. 62: 115-125.

Biggs, D., N. Abel, A. T. Knight, A. Leitch, A. Langston, and N. C. Ban. 2011. "The Implementation Crisis in Conservation Planning: Could "Mental Models" Help?" Conservation Letters. 4: 169-183.

Billionnet, A. 2011. "Solving the Probabilistic Reserve Selection Problem". Ecological Modelling. 222: 546-554. 
Boyd, J., R. S. Epanchin-Niell, and J. Siikamäki. 2012. "Conservation Return on Investment Analysis: A Review of Results, Methods, and New Directions". doi:10.2139/ssrn.1984709.

Boyd, J., R. Epanchin-Niell, and J. Siikamäki. 2015. "Conservation Planning: A Review of Return on Investment Analysis". Review of Environmental Economics and Policy. 9: 23-42.

Bruner, A. G., R. E. Gullison, and A. Balmford. 2004. "Financial Costs and Shortfalls of Managing and Expanding Protected-Area Systems in Developing Countries". BioScience. 54(12): 1119-1126.

Butsic, V., D. J. Lewis, and V. C. Radeloff. 2013. "Reserve Selection with Land Market Feedbacks". Journal of Environmental Management. 114: $276-284$.

Cabeza, M., M. B. Araújo, R. J. Wilson, C. D. Thomas, M. J. R. Cowley, and A. Moilanen. 2004. "Combining Probabilities of Occurrence with Spatial Reserve Design". Journal of Applied Ecology. 41: 252-262.

Camm, J. D., S. Norman, S. Polasky, and A. Solow. 2002. "Nature Reserve Site Selection to Maximize Expected Species Covered". Operations Research. 50(6): 946-955.

Camm, J. D., S. Polasky, A. Solow, and B. Csuti. 1996. "A Note on Optimal Algorithms For Reserve Site Selection". Biological Conservation. 78: 353-355.

Carter, M. and P. Olinto. 2003. "Getting Institutions 'Right' for Whom? Credit Constraints and the Impacts of Property Rights on the Quantity and Composition of Investment". American Journal of Agricultural Economics. 85(1): 173-186.

Carwardine, J., K. A. Wilson, S. A. Hajkowicz, R. J. Smith, C. J. Klein, M. Watts, and H. P. Possingham. 2010. "Conservation Planning When Costs are Uncertain". Conservation Biology. 24: 1529-1537.

Ceauşu, S., I. Gomes, and H. M. Pereira. 2015. "Conservation Planning for Biodiversity and Wilderness: A Real-world Example". Environmental Management. 55: 1168-1180.

Chan, K. M. A., L. Hoshizaki, and B. Klinkenberg. 2011. "Ecosystem Services in Conservation Planning: Targeted Benefits vs. Co-benefits or Costs?" PLoS One 6, e24378.

Church, R. L., D. M. Stoms, and F. W. Davis. 1996. "Reserve Selection as a Maximal Covering Location Problem". Biological Conservation. 76: 105-112. 
Cocks, K. D. and I. A. Baird. 1989. "Using Mathematical Programming to Address the Multiple Reserve Selection Problem: An Example From the Eyre Peninsula, South Australia". Biological Conservation. 49: $113-130$.

Costello, C. and S. Polasky. 2004. "Dynamic Reserve Site Selection". Resource and Energy Economics. 26: 157-174.

Csuti, B., S. Polasky, P. H. Williams, R. L. Pressey, J. D. Camm, M. Kershaw, A. R. Kiester, B. Downs, R. Hamilton, M. Huso, and K. Sahr. 1997. "A Comparison of Reserve Selection Algorithms Using Data on Terrestrial Vertebrates in Oregon". Biological Conservation. 80: 83-97.

Deacon, R. T. and D. P. Parker. 2009. "Encumbering Harvest Rights to Protect Marine Environments: A Model of Marine Conservation Easements". Australian Journal of Agricultural and Resource Economics. 53: 37-58.

DeFries, R., K. K. Karanth, and S. Pareeth. 2010. "Interactions between Protected Areas and Their Surroundings in Human-Dominated Tropical Landscapes". Biological Conservation. 143: 2870-2880.

Delavenne, J., K. Metcalfe, R. J. Smith, S. Vaz, C. S. Martin, L. Dupuis, F. Coppin, and A. Carpentier. 2012. "Systematic Conservation Planning in the Eastern English Channel: Comparing the Marxan and Zonation Decision-Support Tools". ICES Journal of Marine Sciences. 69: $75-83$.

Dickman, A. J. 2010. "Complexities of Conflict: The Importance of Considering Social Factors for Effectively Resolving Human-Wildlife Conflict". Animal Conservation. 13(5): 458-466.

Dissanayake, S. T. M. and H. Önal. 2011. "Amenity Driven Price Effects and Conservation Reserve Site Selection: A Dynamic Linear Integer Programming Approach". Ecological Economics. 70: 2225-2235.

Drechsler, M., F. Watzold, K. Johst, and J. F. Shogren. 2010. "An Agglomeration Payment for Cost-Effective Biodiversity Conservation in Spatially Structured Landscapes". Resoure and Energy Economics. 32(2): 261-275.

Ferraro, P. J. 2003. "The Local Costs of Establishing Protected Areas in Low-Income Nations: Ranomafana National Park, Madagascar". Ecological Economics. 43: 261-275. 
Ferraro, P. J. and M. M. Hanauer. 2011. "Protecting Ecosystems and Alleviating Poverty with Parks and Reserves:"Win-Win" or Tradeoffs?" Environmental and Resource Economics. 48: 269-286.

Ferraro, P. J., M. M. Hanauer, D. A. Miteva, G. J. Canavire-Bacarreza, S. K. Pattanayak, and K. R. E. Sims. 2013. "More Strictly Protected Areas are not Necessarily More Protective: Evidence From Bolivia, Costa Rica, Indonesia, and Thailand". Environmental Research Letters. 8: 025011.

Ferraro, P. J., M. M. Hanauer, and K. R. E. Sims. 2011. "Conditions Associated with Protected Area Success in Conservation and Poverty Reduction". Proceedings Nattional Academy of Sciences USA. 108: 13913-13918.

Ferraro, P. K. and S. K. Pattanayak. 2006. "Money for Nothing? A Call

For Empirical Evaluation of Biodiversity Conservation Investments". PLoS Biology 4, e105.

Fischer, F. 2008. "The Importance of Law Enforcement for Protected Areas: Don't Step Back! Be Honest-Protect!" GAIA - Ecological Perspectives for Science and Society. 17(1): 101-103.

Fox, H. E., M. B. Mascia, X. Basurto, A. Costa, L. Glew, D. Heinemann, L. B. Karrer, S. E. Lester, A. V. Lombana, R. S. Pomeroy, C. A. Recchia, C. M. Roberts, J. N. Sanchirico, L. Pet-Soede, and A. T. White. 2012. "Reexamining the Science of Marine Protected Areas: Linking Knowledge to Action". Conservation Letters. 5: 1-10.

Game, E. T., G. Lipsett-Moore, R. Hamilton, N. Peterson, J. Kereseka, W. Atu, M. Watts, and H. Possingham. 2011. "Informed Opportunism for Conservation Planning in the Solomon Islands". Conservation Letters. 4: 38-46.

Green, A., S. E. Smith, G. Lipsett-Moore, C. Groves, N. Peterson, S. Sheppard, P. Lokani, R. Hamilton, J. Almany, J. Aitsi, and L. Bualia. 2009. "Designing a Resilient Network of Marine Protected Areas for Kimbe Bay, Papua New Guinea". Oryx. 43: 488-498.

Haight, R. G., C. S. Revelle, and S. A. Snyder. 2000. "An Integer Optimization Approach to a Probabilistic Reserve Site Selection Problem". Operational Research. 48: 697-708.

Harrison, P., D. Spring, M. MacKenzie, and R. Mac Nally. 2008. "Dynamic Reserve Design with the Union-Find Algorithm". Ecological Modelling. 215: 369-376. 
Hayes, T. M. 2006. "Parks, People, and Forest Protection: An Institutional Assessment of the Effectiveness of Protected Areas". World Development. 34: 2064-2075.

Hough, J. L. 1988. "Obstacles to Effective Management of Conflicts Between National Parks and Surrounding Human Communities in Developing Countries". Environmental Conservation. 15: 129-136.

Johnson, M., F. Fang, R. Yang, M. Tambe, and H. Albers. 2012. "Patrolling to Maximize Pristine Forest Area". In: Proceedings of the AAAI Spring Symposium on Game Theory for Security, Sustainability and Health.

Joppa, L. N. and A. Pfaff. 2009. "High and Far: Biases in the Location of Protected Areas". PLoS ONE. 4(12): e8273.

Kirkpatrick, J. B. 1983. "An Iterative Method For Establishing Priorities For the Selection of Nature Reserves: An Example From Tasmania". Biological Conservation. 25: 127-134.

Knight, A. T., R. M. Cowling, A. F. Boshoff, S. L. Wilson, and S. M. Pierce. 2011a. "Walking in STEP: Lessons for Linking Spatial Prioritisations to Implementation Strategies". Biological Conservation. 144: 202-211.

Knight, A. T., R. M. Cowling, M. Rouget, A. Balmford, A. T. Lombard, and B. M. Campbell. 2008. "Knowing But Not Doing: Selecting Priority Conservation Areas and the Research-Implementation Gap". Conservation Biology. 22: 610-617.

Knight, A. T., H. S. Grantham, R. J. Smith, G. K. McGregor, H. P. Possingham, and R. M. Cowling. 2011b. "Land Managers' WillingnessTo-Sell Defines Conservation Opportunity for Protected Area Expansion". Biological Conservation. 144: 2623-2630.

Kukkala, A. S. and A. Moilanen. 2013. "Core Concepts of Spatial Prioritisation in Systematic Conservation Planning". Biological Reviews the Cambridge Philosophical Society. 88: 443-464.

Lewis, C. 1996. "Managing Conflicts in Protected Areas". IUCN.

Loos, S. A. 2011. "Marxan Analyses and Prioritization of the Central Interior Ecoregional Assessment". Journal of Ecosystem Management. 12 .

Lusigi, W. 1984. "Integrated Resource Assessment and Management Plan for Western Marsabit District, Northern Kenya". Nairobi: UNESCO. 
Maikhuri, R. K., S. Nautiyal, K. S. Rao, K. Chandrasekhar, R. Gavali, and K. G. Saxena. 2000. "Analysis and Resolution of Protected Area-People Conflicts in Nanda Devi Biosphere Reserve, India". Environmental Conservation. 27(01): 43-53.

Margules, C. R., A. O. Nicholls, and R. L. Pressey. 1988. "Selecting Networks of Reserves to Maximise Biological Diversity". Biological Conservation. 43: 63-76.

Margules, C. R. and R. L. Pressey. 2000. "Systematic Conservation Planning". Nature. 405: 243-253.

Meir, E., S. Andelman, and H. P. Possingham. 2004. "Does Conservation Planning Matter in a Dynamic and Uncertain World?" Ecological Letters. 7: 615-622.

Messer, K. D. 2006. "The Conservation Benefits of Cost-Effective Land Acquisition: A Case Study in Maryland". Journal of Environmental Management. 79: 305-315.

Moilanen, A. 2005. "Reserve Selection Using Nonlinear Species Distribution Models". The American Naturalist. 165: 695-706.

Muller, J. and H. J. Albers. 2004. "Enforcement, Payments, and Development Projects Near Protected Areas: How the Market Setting Determines What Works Where". Resource Energy and Economics. 26: 185-204.

Nackoney, J. and D. Williams. 2013. "A Comparison of Scenarios for Rural Development Planning and Conservation in the Democratic Republic of the Congo". Biological Conservation. 164: 140-149.

Naidoo, R., A. Balmford, P. J. Ferraro, S. Polasky, T. H. Ricketts, and M. Rouget. 2006. "Integrating Economic Costs into Conservation Planning". Trends in Ecology and Evoluation. 21: 681-687.

Nalle, D. J., J. L. Arthur, and J. Sessions. 2002. "Designing Compact and Contiguous Reserve Networks with a Hybrid Heuristic Algorithm". Forest Science. 48: 59-68.

Naughton-Treves, L., J. Alix-Garcia, and C. A. Chapman. 2011. "Lessons About Parks and Poverty from a Decade of Forest Loss and Economic Growth Around Kibale National Park, Uganda". Proceedings of National Academy of Sciences, USA. 108: 13919-13924.

Newburn, D., S. Reed, P. Berck, and A. Merenlender. 2005. "Economics and Land-Use Change in Prioritizing Private Land Conservation". Conservation Biology. 19: 1411-1420. 
Önal, H. 2004. "First-Best, Second-Best, and Heuristic Solutions in Conservation Reserve Site Selection". Biological Conservation. 115: $55-62$.

Onal, H. and R. A. Briers. 2003. "Selection of a Minimum-Boundary Reserve Network Using Integer Programming". Proceedings of the Royal Society B: Biological Sciences. 270: 1487-1491.

Önal, H. and Y. Wang. 2008. "A Graph Theory Approach For Designing Conservation Reserve Networks with Minimal Fragmentation". Networks. 51: 142-152.

Orestes Cerdeira, J., K. J. Gaston, and L. S. Pinto. 2005. "Connectivity in Priority Area Selection for Conservation". Environmental Modeling and Assessment. 10: 183-192.

Ostrom, E. and C. Hess. 2010. "Private and Common Property Rights". In: Property Law and Economics. Ed. by B. Bouckaert.

Parkhurst, G. M. and J. F. Shogren. 2007. "Spatial Incentives to Coordinate Contiguous Habitat". Ecological Economics. 64(December): 344-355.

Parkhurst, G. M., J. F. Shogren, C. Bastian, P. Kivi, J. Donner, and R. Smith. 2002. "Agglomeration Bonus: An Incentive Mechanism to Reunite Fragmented Habitat For Biodiversity Conservation". Ecological Economics. 41(2): 305-328.

Pereira, H. M., S. Ferrier, M. Walters, G. N. Geller, R. H. G. Jongman, R. J. Scholes, M. W. Bruford, N. Brummitt, S. H. M. Butchart, A. C. Cardoso, N. C. Coops, E. Dulloo, D. P. Faith, J. Freyhof, R. D. Gregory, C. Heip, R. Höft, G. Hurtt, W. Jetz, D. S. Karp, M. A. McGeoch, D. Obura, Y. Onoda, N. Pettorelli, B. Reyers, R. Sayre, J. P. W. Scharlemann, S. N. Stuart, E. Turak, M. Walpole, and M. Wegmann. 2013. "Ecology. Essential Biodiversity Variables". Science. 339: 277-278.

Pfaff, A., J. Robalino, E. Lima, C. Sandoval, and L. D. Herrera. 2014. "Governance, Location and Avoided Deforestation From Protected Areas: Greater Restrictions Can Have Lower Impact, Due to Differences in Location". World Development. 55: 7-20.

Plantinga, A. J. 2007. "The Economics of Conservation Easements". In: Land Policies and their Outcomes. Proceedings of the 2006 Land Policy Conference. Lincoln Institute of Land Policy. 
Polasky, S. 2006. "You Can't Always Get What You Want: Conservation Planning with Feedback Effects". Proceedings of National Academy of Sciences USA. 103(14): 5245-5246.

Polasky, S., J. D. Camm, and B. Garber-Yonts. 2001. "Selecting Biological Reserves Cost-Effectively: An Application to Terrestrial Vertebrate Conservation in Oregon". Land Economics. 77: 68-78.

Polasky, S., J. D. Camm, A. R. Solow, B. Csuti, D. White, and R. Ding. 2000. "Choosing Reserve Networks with Incomplete Species Information". Biological Conservation. 94: 1-10.

Polasky, S., E. Nelson, J. Camm, B. Csuti, P. Fackler, E. Lonsdorf, C. Montgomery, D. White, J. Arthur, B. Garber-Yonts, R. Haight, J. Kagan, A. Starfield, and C. Tobalske. 2008. "Where to Put Things? Spatial Land Management to Sustain Biodiversity and Economic Returns". Biological Conservation. 141: 1505-1524.

Polasky, S., E. Nelson, E. Lonsdorf, P. Fackler, and A. Starfield. 2005. "Conserving Species in a Working Landscape: Land Use with Biological and Economic Objectives". Ecological Applications. 15: 13871401.

Pressey, R. L. and M. C. Bottrill. 2009. "Approaches to Landscape- and Seascape-Scale Conservation Planning: Convergence, Contrasts and Challenges". Oryx. 43: 464-475.

Pressey, R. L., H. P. Possingham, and J. R. Day. 1997. "Effectiveness of Alternative Heuristic Algorithms for Identifying Indicative Minimum Requirements for Conservation Reserves". Biological Conservation. 80: 207-219.

Pressey, R. L., H. P. Possingham, and C. R. Margules. 1996. "Optimality in Reserve Selection Algorithms: When Does it Matter and How Much?" Biological Conservation. 76: 259-267.

Robalino, J. and L. Villalobos. 2015. "Protected Areas and Economic Welfare: An Impact Evaluation of National Parks on Local Workers' Wages in Costa Rica". Environment and Development Economics. 20(03): 283-310.

Robinson, E. J. Z., H. J. Albers, and G. M. Busby. 2013. "The Impact of Buffer Zone Size and Management on Illegal Extraction, Park Protection, and Enforcement". Ecological Economics. 92: 96-103. 
Robinson, E. J. Z., H. J. Albers, and S. L. Kirama. 2014. "The Role of Incentives For Sustainable Implementation of Marine Protected Areas: An Example From Tanzania". International Journal of Sustainable Society. 6: 28-46.

Robinson, E. J. Z., H. J. Albers, and J. C. Williams. 2011. "Sizing Reserves within a Landscape: The Roles of Villagers' Reactions and the Ecological-Socioeconomic Setting". Land Economics. 87: 233-249.

Robinson, E. J. Z., A. M. Kumar, and H. J. Albers. 2010. "Protecting Developing Countries' Forests: Enforcement in Theory and Practice". Journal of Natural Resources Policy Research. 2: 25-38.

Robinson, E. J. Z., J. C. Williams, and H. J. Albers. 2002. "The Impact of Markets and Policy on Spatial Patterns of Non-Timber Forest Product Extraction". Land Economics. 78(2): 260-271.

Rodrigues, A. S. L. and K. J. Gaston. 2002. "Optimisation in Reserve Selection Procedures - Why Not?" Biological Conservation. 107: 123-129.

Sabbadin, R., D. Spring, and C.-E. Rabier. 2007. "Dynamic Reserve Site Selection Under Contagion Risk of Deforestation". Ecological Modelling. 201: 75-81.

Sanchirico, J. N. 2005. "Additivity Properties in Metapopulation Models: Implications For the Assessment of Marine Reserves". Journal of Environmental Economics and Management. 49: 1-25.

Sanchirico, J. N. and P. M. Emerson. 2002. Marine Protected Areas: Economic and Social Implications. Washington, DC: Resources for the Future.

Sanchirico, J. N. and J. E. Wilen. 2001. "A Bioeconomic Model of Marine Reserve Creation". Journal of Environmental Economics and Management. 42: 257-276.

Santangeli, A., E. Di Minin, and B. Arroyo. 2014. "Bridging the Research Implementation Gap - Identifying Cost-Effective Protection Measures for Montagu's Harrier Nests in Spanish farmlands". Biological Conservation. 177: 126-133.

Schnier, K. E. 2005. "Biological "Hot Spots" and Their Effect on Optimal Bioeconomic Marine Reserve Formation". Journal of Ecological Economics. 52: 453-468. 
Shavell, S. M. and A. M. Polinsky. 2000. "The Fairness of Sanctions: Some Implications For Optimal Enforcement Policy". American Law and Economic Review. 2: 223-237.

Siitonen, P., A. Tanskanen, and A. Lehtinen. 2002. "Method for Selection of Old-Forest Reserves". Conservation Biology. 16: 1398-1408.

Sims, K. R. E. 2010. "Conservation and Development: Evidence From Thai Protected Areas". Journal of Environmental Economics and Management. 60: 94-114.

Smith, M. D. and J. E. Wilen. 2003. "Economic Impacts of Marine Reserves: The Importance of Spatial Behavior". Journal of Environmental Economics and Management. 46: 183-206.

Snyder, S. A., R. G. Haight, and C. S. ReVelle. 2004. "A Scenario Optimization Model For Dynamic Reserve Site Selection". Environmental Modelling and Assessment. 9: 179-187.

Stoneham, G., V. Chaudhri, A. Ha, and L. Strappazzon. 2003. "Auctions for Conservation Contracts: An Empirical Examination of Victoria's BushTender Trial". Australian Journal of Agricultural and Resource Economics. 47: 477-500.

The World Bank, World Development Indicators. 2015a. "Marine Protected Areas (\% of Territorial Waters) [Data file]". Available from: http://data.worldbank.org/indicator/ER.MRN.PTMR.ZS.

The World Bank, World Development Indicators. 2015b. "Terrestrial protected areas (\% of Total Land Area) [Data file]". Available from: http://data.worldbank.org/indicator/ER.LND.PTLD.ZS.

Tóth, S. F., R. G. Haight, and L. W. Rogers. 2011. "Dynamic Reserve Selection: Optimal Land Retention with Land-Price Feedbacks". Operational Research. 59: 1059-1078.

Tóth, S. F., R. G. Haight, S. A. Snyder, S. George, J. R. Miller, M. S. Gregory, and A. M. Skibbe. 2009. "Reserve Selection with Minimum Contiguous Area Restrictions: An Application to Open Space Protection Planning in Suburban Chicago". Biological Conservation. 142: $1617-1627$.

Underhill, L. G. 1994. "Optimal and Suboptimal Reserve Selection Algorithms". Biological Conservation. 70: 85-87.

UNEP-WCMC. 2016a. The State of Biodiversity in Africa: A MidTerm Review of Progress Towards the Aichi Biodiversity Targets. Cambridge, UK: UNEP-WCMC. 
UNEP-WCMC. 2016b. The State of Biodiversity in Asia and the Pacific: A Mid-Term Review of Progress Towards the Aichi Biodiversity Targets. Cambridge, UK: UNEP-WCMC.

UNEP-WCMC. 2016c. The State of Biodiversity in Latin America and the Caribbean: A Mid-Term Review of Progress Towards the Aichi Biodiversity Targets. Cambridge, UK: UNEP-WCMC.

URT: United Republic of Tanzania. 1994. "The Marine Parks and Reserves Act". Available from https://www.ofdc.org.tw/components/ Editor/webs/files/Tanzania_Marine_park_and_reserves_Act_ 1994.pdf [retrived 15 July 2015].

Vanderkam, R. P. D., Y. F. Wiersma, and D. J. King. 2007. "Heuristic Algorithms vs. Linear Programs For Designing Efficient Conservation Reserve Networks: Evaluation of Solution Optimality and Processing Time". Biological Conservation. 137: 349-358.

Vane-Wright, R. I., C. J. Humphries, and P. H. Williams. 1991. "What to Protect? - Systematics and the Agony of Choice". Biological Conservation. 55: 235-254.

Wang, Y. and H. Önal. 2016. "Optimal Design of Compact and Connected Nature Reserves For Multiple Species". Conservation Biology. 30: 413-424.

Watts, M. E., C. K. Klein, R. R. Stewart, I. R. Ball, and H. P. Possingham. 2008a. Marxan with Zones (v. 1. 0. 1): Conservation Zoning using Spatially Explicit Annealing, a Manual. Brisbane: University of Queensland.

Watts, M., C. Steinback, and C. Klein. 2008b. "Applying Marxan with Zones to North Central Coast of California". User Guide.

Wätzold, F. and K. Schwerdtner. 2005. "Why be Wasteful When Preserving A Valuable Resource? A Review Article on the Cost-Effectiveness of European Biodiversity Conservation Policy". Biological Conservation. 123: 327-338.

West, P., J. Igoe, and D. Brockington. 2006. "Parks and Peoples: The Social Impact of Protected Areas". Annual Review of Anthropology. 35: 251-277.

Whitehead, A. L., H. Kujala, C. D. Ives, A. Gordon, P. E. Lentini, B. A. Wintle, E. Nicholson, and C. M. Raymond. 2014. "Integrating Biological and Social Values When Prioritizing Places For Biodiversity Conservation". Conservation Biology. 28: 992-1003. 
Wilen, J. E., M. D. Smith, D. Lockwood, and L. W. Botsford. 2002. "Avoiding Surprises: Incorporating Fisherman Behavior into Management Models". Bulletin of Marine Sciences. 70: 553-575.

Williams, J. C. and C. S. ReVelle. 1998. "Reserve Assemblage of Critical Areas: A Zero-One Programming Approach". European Journal of Operational Research. 104: 497-509.

Wilson, K., R. L. Pressey, A. Newton, M. Burgman, H. Possingham, and C. Weston. 2005. "Measuring and Incorporating Vulnerability into Conservation Planning". Environmental Management. 35: 527-543. Zhang, J. and M. D. Smith. 2010. "Heterogeneous Response to Marine Reserve Formation: A Sorting Model Approach". Environmental and Resource Economics. 49: 311-325. 